\title{
Very low-calorie diet in patients with longstanding type 2 diabetes mellitus: a study of real-world outcomes
}

\author{
MELANIE NANA, ${ }^{1 *}$ SACHA L MOORE, ${ }^{2 *}$ RIYANATH LOGANATHAN, ${ }^{2}$ VICTORIA WILLIAMS, ${ }^{3}$ \\ MOHAMMAD RAHMAN, ${ }^{4}$ ELAINE JENNINGS, ${ }^{3}$ ANTHONY DIXON, ${ }^{4}$ LN RAO BONDUGULAPATI ${ }^{4}$
}

\begin{abstract}
Introduction: There is a paucity of evidence regarding the efficacy of a very low-calorie diet (VLCD) in the real-world setting. We evaluated outcomes in patients with type 2 diabetes mellitus (T2DM) who underwent VLCD.

Methods: This retrospective observational study included all patients who had undergone VLCD from 2014 to 2017 ( $n=61$ ). The VLCD consisted of an eight-week $800 \mathrm{kcal} /$ day dietary restriction. Metabolic parameters and medications were recorded at baseline, immediately post-VLCD and at 6 and 12 months.

Results: There was a significant reduction in weight of $9.96 \mathrm{~kg}$ $(p<0.001)$ immediately post-VLCD, with net weight loss sustained to 12 months $(p<0.05)$. There was a significant reduction in body mass index (BMI) sustained to 12 months $(p<0.05)$. Paired $\mathrm{HbA}_{1 c}$ data were available for 38 patients. There was a significant reduction in $\mathrm{HbA}_{1 \mathrm{c}}$ of $13.29 \mathrm{mmol} / \mathrm{mol}$ immediately post-VLCD $(p<0.001)$, however no significant reduction was observed at 12 months ( $p>0.05$ ). $78.7 \%$ patients had a reduction in T2DM medication burden postVLCD, sustained in $44.3 \%$ of patients at 12 months. Analysis of patients with T2DM diagnosis duration $>6$ years demonstrated statistically significant weight loss sustained to 12 months $(p<0.001)$.

Conclusion: Our results demonstrate sustained reduction in $\mathrm{BMI}$ and weight, reduction in medication burden and temporary reduction in $\mathrm{HbA}_{1 \mathrm{c}}$ in patients with T2DM undertaking a VLCD in the real-world setting

Br J Diabetes 2021;21:216-221
\end{abstract}

${ }^{*} \mathrm{MN}$ and SLM contributed equally to this work.

Specialist Registrar, Department of Diabetes and Endocrinology, Wrexham Maelor Hospital, Wrexham, UK

2 Foundation Year 2 Doctor, Department of Diabetes and Endocrinology, Wrexham Maelor Hospital, Wrexham, UK

3 Dietician, Department of Diabetes and Endocrinology, Wrexham Maelor Hospital, Wrexham, UK

4 Consultant Endocrinologist, Department of Diabetes and Endocrinology, Wrexham Maelor Hospital, Wrexham, UK

Address for correspondence: Dr LN Rao Bondugulapati Consultant Endocrinologist, Department of Diabetes and Endocrinology, Wrexham Maelor Hospital, Wrexham, LL13 7TD, UK Tel: +44 1978727107

E-mail: rao.bondugulapati@wales.nhs.uk

https://doi.org/10.15277/bjd.2021.316
Key words: very low-calorie diet (VLCD), obesity, type 2 diabetes mellitus (T2DM), weight, glycosylated haemoglobin $\left(\mathrm{HbA}_{1 \mathrm{c}}\right)$

\section{Introduction}

Type 2 diabetes mellitus (T2DM) is a metabolic disorder characterised by peripheral insulin resistance and/or insulin deficiency. ${ }^{1}$ It is rapidly becoming an epidemic, with the global prevalence of diabetes amongst adults aged over 18 years rising from $4.7 \%$ in 1980 to $8.5 \%$ in $2014 .{ }^{2}$ Diabetes mellitus (DM) carries a significant risk of morbidity and mortality, currently representing the fifth largest cause of death globally. ${ }^{3}$

A study from the UK published in 2012 predicted that the annual cost of direct patient care for people with diabetes (treatment, intervention and management of complications) will increase from $\mathrm{f} 9.8$ billion to $\mathrm{f} 16.9$ billion in the next 25 years. $4 \mathrm{~A}$ significant proportion of this cost is attributed to T2DM, which accounts for $90 \%$ of all DM.

The relationship between T2DM and obesity is well established. For every $1 \mathrm{~kg}$ of weight gain there is a $9 \%$ increase in the relative risk of developing T2DM. ${ }^{5}$ Weight reduction is the principal management strategy for the prevention and management of T2DM as it reduces insulin resistance, improves glycaemic control and reduces cardiovascular risk and mortality. ${ }^{2}$

T2DM has historically been considered a progressive and irreversible condition with a high prevalence of microvascular complications and loss of beta cell function frequently present at diagnosis, thus treatment was aimed at slowing the progression of such complications. ${ }^{6}$ In the last two decades, however, it has been observed that patients with T2DM may go into remission following bariatric surgery ${ }^{7-8}$ Diabetes remission, as defined by the Association of British Clinical Diabetologists ( $A B C D$ ) and the Primary Care Diabetes Society (PCDS) in a recent consensus statement, is the "achievement of glycaemia below the threshold currently used for the diagnosis of T2DM, which is sustained for at least 6 months off glucose lowering therapy". ${ }^{9}$ Results of studies investigating the role of bariatric surgery in T2DM remission have been remarkable and this link is now considered well-established.

More recently, the feasibility of achieving remission through methods other than surgery has been demonstrated, most notably with the use of a low-calorie diet (LCD) or very low-calorie diet $(\mathrm{VLCD}){ }^{10-13} \mathrm{VLCD}$ is defined as a diet of less than $800 \mathrm{kcal}$ per day. ${ }^{14}$ The percentage energy derived from protein compared with car- 
bohydrate and fat is increased, enhancing lipolysis and ketosis while preventing a negative nitrogen balance, thus sparing lean body mass..$^{15}$ In principle, the visceral fat reduction triggered by this acute calorie deficit may result in improved hepatic insulin sensitivity and pancreatic beta-cell function, which in turn delivers improvement in glycaemic control that is comparative with bariatric surgery. ${ }^{16-19}$ Recent clinical trials have provided firm evidence for the efficacy of VLCD in a controlled setting with carefully selected patients; ${ }^{10,11}$ however, to date there is a paucity in real-world evidence of VLCD programme use in patients with a wide spectrum of T2DM disease severity and duration. Moreover, there are limited data regarding long-term outcomes following VLCD. In this study we aim to evaluate metabolic and glycaemic outcomes for patients with T2DM who had undertaken a VLCD in our secondary care institution.

\section{Methods}

A service which supported patients undertaking a VLCD was introduced in our centre in 2014. The service was dietetics-led; however, there was substantial diabetologist involvement due to the broad selection criteria. In contrast to published literature, patients were not excluded on the basis of their duration of diabetes or degree of polypharmacy and patients taking insulin therapy were eligible for inclusion.
The service model is outlined in Figure 1. Our programme involved the use of $600 \mathrm{kcal}$ of meal replacement products per day with up to $200 \mathrm{kcal}$ ring-fenced to allow the patient to choose and make a vegetable or salad-based meal. Weight was measured weekly. Support was provided in the form of weekly dietitian-led telephone calls with group meetings at weeks 4 and 8 to provide ongoing education and facilitate troubleshooting.

\section{Data collection}

Following local institutional approval (registration no. 18/412), all patients who had undertaken a VLCD programme between the inception of the service (August 2014) and December 2017 were retrospectively identified $(n=61)$. Only patients who had completed the full VLCD course were included. Electronic patient records were accessed with clinic letters, investigation results and dietetic notes reviewed. Data were collated onto a secure electronic database containing categories encompassing patient demographics, weight change, glycaemic and metabolic parameters. In addition, the documented medications of patients were recorded at each time point. The medication burden was assessed between time points and deemed to have decreased if the overall number or dose of diabetes-related medications (metformin, sulfonylurea, sodiumglucose cotransporter-2 (SGLT2) inhibitors, glucagon-like peptide-1 (GLP1) agonists, dipeptidyl peptidase-4 (DPP4) inhibitors,

Figure 1. The VLCD model used at our institution

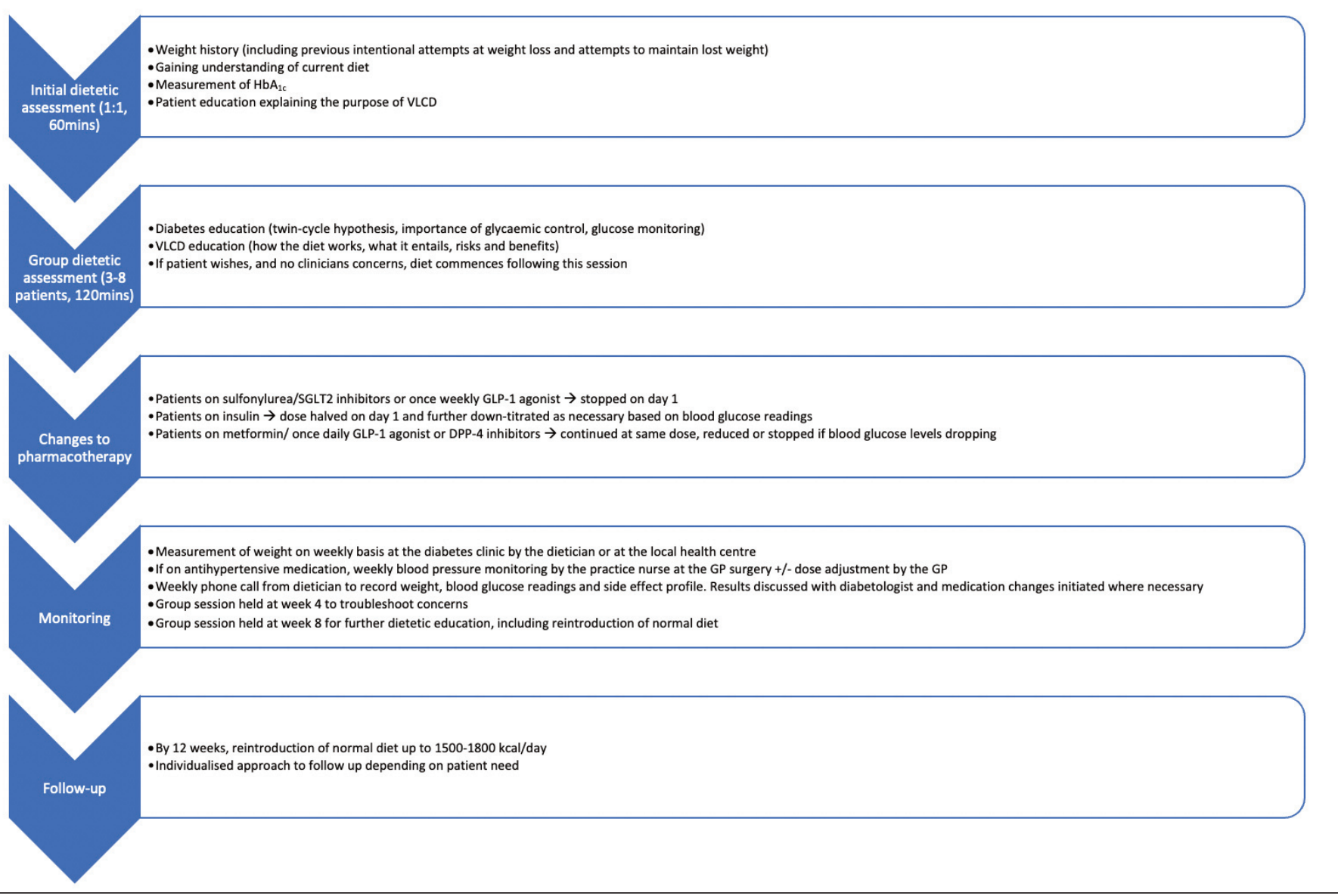


thiazolidinediones, insulin) had decreased between the two time points.

The primary outcome measure was change in weight between pre-VLCD and time points of immediately post-diet, 6 months postdiet and 12 months post-diet. Key secondary outcomes included changes in $\mathrm{HbA}_{1 \mathrm{c}}$ and medication burden at equivalent time points. Sub-group analysis assessed these outcomes with patients according to duration of diabetes and duration of their follow-up postVLCD.

\section{Data analysis}

Statistical analysis was undertaken in SPSS version 25.0 for Windows (IBM corporation). The Shapiro-Wilk test (if $n<50$ ) or Kolmogorov-Smirnov test (if $n>50$ ) was performed to assess for normality of distribution, defined as $p>0.05$. Parametric data were analysed using paired-samples t-test for pre- and post-VLCD values and independent samples t-test for non-paired data. Non-parametric data were analysed using Mann-Whitney $U$ test and $X 2$ test as appropriate. Parametric data are presented as mean \pm standard deviation unless otherwise stated. Non-parametric data are presented as mediantrange/interquartile range unless otherwise stated. Statistical significance was defined as per the standard value of $p<0.05$.

\section{Results}

\section{Baseline characteristics}

Sixty-one patients commenced on VLCD between August 2014 and December 2017. The mean age of patients was 55.20 years (range 36-75 years). There were 34 males and 27 females (M:F=1.26:1). The mean number of weeks on the diet was 7.97 weeks ( \pm 0.26 weeks); while most patients completed 8 weeks, a small number of patients completed just over 7 weeks but were deemed to have completed the course by the service clinicians. The mean starting weight for patients was $108.16 \mathrm{~kg}( \pm 19.08 \mathrm{~kg})$. Mean baseline BMI was $38.21 \mathrm{~kg} / \mathrm{m}^{2}\left( \pm 6.25 \mathrm{~kg} / \mathrm{m}^{2}\right)$. The mean starting $\mathrm{HbA}_{1 \mathrm{c}}$ was $79.60 \mathrm{mmol} / \mathrm{mol}( \pm 16.99 \mathrm{mmol} / \mathrm{mol})$. The mean length of follow-up post-completion was 23.93 months $( \pm 16.86$ months). There were no documented adverse events.

\section{Impact of VLCD on metabolic parameters}

Weight measurements were obtained for pre-VLCD, immediately post-VLCD, 6 months post-VLCD and 12 months post-VLCD. The mean starting weight for patients was $108.16 \mathrm{~kg}( \pm 19.08 \mathrm{~kg})$. There was a significant reduction in mean weight post-VLCD of $9.96 \mathrm{~kg}( \pm 6.02 \mathrm{~kg}, 95 \% \mathrm{Cl} 8.32$ to $11.61 ; \mathrm{p}<0.001)$, equating to a $9.3 \%$ loss in total body weight. This significant reduction was maintained to 6 months post-VLCD with a mean weight loss compared with baseline of $10.93 \mathrm{~kg}( \pm 8.27 \mathrm{~kg}, 95 \% \mathrm{Cl} 8.09$ to 13.77 ; $p<0.001$ ), equating to a $10.1 \%$ loss in total body weight. Despite moderate weight gain between 6 and 12 months post-VLCD, there was still a significant net reduction in body weight of $5.67 \mathrm{~kg}$ $( \pm 11.64 \mathrm{~kg})$ at 12 months compared with pre-VLCD $(95 \% \mathrm{Cl} 1.16$ to $10.19 ; p=0.016)$, equating to an overall weight loss of $5.2 \%$ at 12 months compared with baseline.

Paired BMI data were available for 27 patients at the baseline and 12 month time points. Mean baseline BMI was $38.21 \mathrm{~kg} / \mathrm{m}^{2}$ $\left( \pm 6.25 \mathrm{~kg} / \mathrm{m}^{2}\right)$. Mean BMl at 12 months was $36.01 \mathrm{~kg} / \mathrm{m}^{2}( \pm 7.28$ $\mathrm{kg} / \mathrm{m}^{2}$ ), equating to a significant mean reduction in BMI of 2.20 $\mathrm{kg} / \mathrm{m}^{2}$ (95\% Cl 0.53 to 3.84; $\left.\mathrm{p}=0.01\right)$.

Paired sample $\mathrm{HbA}_{1 \mathrm{c}}$ readings were available for 38 patients for pre-VLCD, post-VLCD, 6 months post-VLCD and 12 months postVLCD. The mean starting $\mathrm{HbA}_{1 \mathrm{c}}$ was $79.60 \pm 16.99 \mathrm{mmol} / \mathrm{mol}$ $(9.4 \pm 3.7 \%)$. There was a significant reduction in $\mathrm{HbA}_{1 \mathrm{c}}$ of $13.29 \pm 17.65 \mathrm{mmol} / \mathrm{mol}(3.4 \pm 3.8 \%)$ between pre-VLCD and immediately post-VLCD time points $(95 \% \mathrm{Cl} 7.49$ to 19.09 ; $\mathrm{p}<0.001)$. However, a significant overall net reduction in $\mathrm{HbA}_{1 \mathrm{c}}$ was not sustained to 6 months or 12 months ( $p>0.05$ ).

\section{Impact of VLCD on medication burden}

The results are shown in Table 1. Of note, $78.7 \%$ of patients were prescribed fewer diabetes-related medications after completing VLCD, with $57.4 \%$ of patients continuing to have a reduced medication burden at 6 months and $44.3 \%$ of patients at 12 months.

Twenty-three of the 61 patients (37.7\%) were prescribed insulin prior to commencing VLCD. Data were obtained for changes in insulin dosage immediately post-VLCD, at 6 months and at 12 months. The results are shown in Table $2.95 .7 \%$ of patients were using less insulin after completing VLCD, with $65.2 \%$ of patients maintaining this reduction to 6 months and $52.1 \%$ to 12 months. Additionally, 6/23 (26.1\%) patients no longer required any insulin at all 12 months post-VLCD.

The cost of diabetic medications (not including insulin) was approximated using National Health Service (NHS) pricing guidelines. The mean cost of diabetic medications per patient per month prior to undertaking VLCD was $f 56.29$. The mean cost of diabetic medication per patient per month at 12 months post-VLCD

Table 1 Medication changes in patients on a very low-calorie diet

\begin{tabular}{llll}
\hline & Post-VLCD & 6 months & 12 months \\
Lower net medication burden & $48(78.7)$ & $35(57.4)$ & $27(44.3)$ \\
Same net medication burden & $5(8.2)$ & $10(16.4)$ & $11(18.0)$ \\
Higher net medication burden & $0(0)$ & $1(1.6)$ & $4(6.6)$ \\
N/A & $8(13.1)$ & $15(24.6)$ & $19(31.1)$
\end{tabular}

Data are presented as $n(\%)$

N/A denotes data not available or applicable and includes both patients for whom there was a lack of documentation of medication changes or who had not been on any diabetes-related medication at any time.

Table 2 Insulin dose changes in patients on a very low-calorie diet

\begin{tabular}{llll}
\hline & Post-VLCD & 6 months & 12 months \\
Lower net insulin prescription & $22(95.7)$ & $15(65.2)$ & $12(52.1)$ \\
Same net insulin prescription & $0(0)$ & $2(8.7)$ & $1(4.3)$ \\
Higher net insulin prescription & $1(4.3)$ & $2(8.7)$ & $2(8.7)$ \\
N/A & 0 & $4(17.4)$ & $8(34.9)$ \\
Data are presented as n (\%). N/A denotes data not available &
\end{tabular}


completion was $f 40.40$. This equates to an estimated mean cost saving of $f 15.89$ per patient per month $(28.23 \%$ estimated cost saving, $\mathrm{p}=0.024$ ).

\section{VLCD in patients with a diagnosis of T2DM for over five years}

Patients were stratified according to duration of diagnosis of T2DM. Nine of $61(14.8 \%)$ patients had received a diagnosis of T2DM $\leq 5$ years of starting VLCD, 10/61 (16.4\%) patients had been diagnosed for $6-10$ years, $14 / 61$ (23.0\%) had been diagnosed for $11-15$ years and $15 / 61$ (24.6\%) patients had been diagnosed for $\geq 16$ years (24.6\%). Data on duration of diagnosis were unobtainable for 13 (21.3\%) patients.

Patients with a T2DM diagnosis for $>5$ years $(n=39)$ had a significant reduction in weight at post-VLCD and 6 months ( $p<0.001$ ) and 12 months ( $p=0.013)$. There was also a significant reduction in HbA1c $(p=0.001)$ in this cohort immediately post-VLCD, but this was not sustained to 6 or 12 months.

Patients with a T2DM diagnosis for $>10$ years $(n=29)$ had a significant reduction in weight at post-VLCD and 6 months ( $p<0.001)$, which was not sustained at 12 months $(p=0.137)$. A significant reduction in $\mathrm{HbA}_{1 c}(\mathrm{p}=0.007)$ was noted post-VLCD in this cohort, not sustained to 6 or 12 months.

Patients with a T2DM diagnosis for $>15$ years $(n=15)$ demonstrated a significant reduction in weight at post-VLCD and at 6 months $(p<0.001)$, which was not sustained at 12 months $(\mathrm{p}=0.532)$. No significant reduction in $\mathrm{HbA}_{1 c}$ was noted at any time point in this cohort.

\section{Discussion}

This retrospective observational study provides valuable real-world outcomes of VLCD utilisation in patients with a spectrum of T2DM duration and severity. Notably, our results demonstrate significant weight loss in the overall cohort, sustained to 6 and 12 months post completion of the diet, that support the conclusions of tightly managed randomised controlled trials (RCTs). ${ }^{10,11}$

The eligibility criteria for patients undertaking VLCD at our institution were broad; patients were not excluded on the basis of their age, duration of T2DM or medication regimen. In contrast, much of the evidence surrounding VLCD in T2DM comes from interventional trials with strict inclusion and exclusion criteria; the Counterpoint study restricted inclusion to patients aged 35-65 years with an $\mathrm{HbA}_{1 \mathrm{c}}$ of $48-75 \mathrm{mmol} / \mathrm{mol}$, BMl $25-45 \mathrm{~kg} / \mathrm{m}^{2}$ and diabetes duration $<4$ years, while the DiRECT trial included patients aged 20-65 years with an $\mathrm{HbA}_{1 \mathrm{c}}<108 \mathrm{mmol} / \mathrm{mol}$, BMl 27-45 $\mathrm{kg} / \mathrm{m}^{2}$ and diabetes duration $<6$ years. ${ }^{10,11,20,21}$ While the breadth of disease severity and baseline characteristics have the potential to confound outcomes in our study, the significant weight loss we demonstrate in our overall cohort supports the assertion that VLCD can be effective, at least in the short to medium term, regardless of T2DM disease duration or severity.

Indeed, significant weight loss was seen in the whole cohort with a net reduction of $5.2 \%(5.67 \mathrm{~kg})$ sustained at 12 months follow-up. While this percentage is lower than the 12 -month results in the DiRECT trial (which may be the result of a less intensive follow-up regime in the real-world setting), it nonetheless represents clinically significant weight loss. Previous studies of VLCD in T2DM have demonstrated the benefits of weight loss following acute calorie deficit on pericardial fat and on markers of renal and hepatic health. ${ }^{22,23}$ Information on lipid profiles and measures of hepatic function were limited in our cohort of patients and were therefore not available for analysis, a limitation of this retrospective approach to this study. Nonetheless, it is likely that an initial mean weight loss of approximately $10 \%$ and sustained weight loss of approximately $5 \%$ will have clinically relevant benefits for a number of obesity- related co-morbidities. ${ }^{24}$ Meanwhile, our subgroup analysis seems to suggest that there is little sustained benefit in terms of weight loss and $\mathrm{HbA}_{1 c}$ following VLCD in patients with a diabetes duration $>10$ years (although their medication burden may be reduced).

Despite initial significant reduction in $\mathrm{HbA}_{1 c}$ in our cohort, this was not sustained to 6 or 12 months. This is in contrast to the DiRECT trial, where there was an overall significant reduction in $\mathrm{HbA}_{1 \mathrm{c}}$ of $0.9 \%$ at 12 months. ${ }^{11}$ Notably, in DiRECT, $\mathrm{HbA}_{1 \mathrm{c}}$ reduction was proportionate to weight loss; $7 \%$ patients who lost $0-5 \mathrm{~kg}$ at 12 months achieved remission of T2DM, with this rising to $34 \%$ in patients who lost $5-10 \mathrm{~kg}$. Given the mean weight loss at 12 months in our study was approximately $5 \mathrm{~kg}$ and paired $\mathrm{HbA}_{1 \mathrm{c}}$ readings were only available for 38 patients, this may help to explain the lack of statistical significance in $\mathrm{HbA}_{1 \mathrm{c}}$ improvement at 12 months.

As an evaluation of standard care, our study did not have the intensive follow-up from which patients in a trial setting would benefit; while in DiRECT patients received a review at the end of week 1, then a face-to-face review every other week until week 18 , and then a face-to-face monthly review thereafter. In our centre, patients received telephone contact from dietetic staff during weeks 1-3 and 5-7, with a face-to-face group session at weeks 4 and 8 of the intervention period. Subsequently, patients returned to normal standard of care (for most, 6-monthly secondary care appointments). It is likely that intensive contact may have contributed to the improved $\mathrm{HbA}_{1 \mathrm{c}}$ and weight loss outcomes seen in DiRECT along with DiRECT patients having shorter duration of T2DM $<6$ years), which would mean that they had higher chances of reinstituting intrinsic insulin production. However, this has to be balanced against the resource implications of a high number of face-to-face appointments in a publicly-funded healthcare system. In future, it may be beneficial to have regular (3-monthly) $\mathrm{HbA}_{1 \mathrm{c}}$ checks with telephone follow-up to identify and address worsening glycaemic control at an early enough stage to facilitate intervention and ultimately maintain the post-VLCD HbA $1 c$ improvement seen in our study. Additionally, due to the retrospective nature of our study and the lack of structured follow-up, $\mathrm{HbA}_{1 c}$ values were often missing at the 6 and 12 month time points, and it may be that a more structured approach to follow-up would enable patients to achieve positive outcomes in $\mathrm{HbA}_{1 \mathrm{c}}$.

Our results demonstrate a significant reduction in diabetes medication burden post VLCD, sustained in almost half of patients to 6 and 12 months. Medication burden was also assessed in DiRECT; patients in the intervention group had a mean reduction of 0.8 oral 


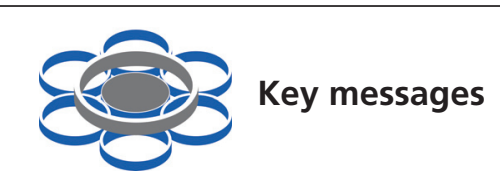

- VLCD can be an effective treatment in T2DM population up to 10 years from diagnosis

- An element of patient food choices can be safely incorporated within a VLCD programme without compromising efficacy

- Re-introduction of medications post-VLCD is a critical balance between minimising medication burden and optimising $\mathrm{HbA}_{1 \mathrm{c}}$

antidiabetic medications per patient at 12 months. ${ }^{11}$ While improvement in $\mathrm{HbA}_{1 \mathrm{c}}$ remained significant at 12 months alongside the medication reduction in DiRECT, in our study a significant reduction in $\mathrm{HbA}_{1 c}$ was not maintained in line with reduction in medication burden. Notably, the number of medications at baseline was greater per patient in our study, indicating greater medication burden and thus posing a different challenge in managing medications during and post-VLCD. Additionally, approximately one in four patients who were prescribed insulin pre-VLCD in our study were no longer requiring insulin at 12 months, and in those originally prescribed insulin who had an improvement in $\mathrm{HbA}_{1 c}, 80 \%$ also saw a concomitant reduction in insulin burden. Being on insulin was an exclusion criterion for DiRECT, thus limiting the ability to draw comparisons between trial and real-world evidence, but the reduction in insulin burden seen in this study is promising.

Re-introduction of medications post-VLCD is a critical balance between minimising medication burden and optimising $\mathrm{HbA}_{1 \mathrm{c}}$. There is a lack of evidence base informing this balance, and thus reintroduction of medications is often managed on a patientby-patient and clinician-by-clinician basis. Given the more intensive follow-up regimen in DiRECT, it is possible that reintroduction of medication was managed more closely and that, with more structured follow-up post-VLCD, a reduction in medication burden can be achieved alongside improvement in $\mathrm{HbA}_{1 c}$ in the real-world setting. Further work is needed to establish the optimal pathway for reintroduction of medications post-VLCD. Additionally, whilst we have noted a cost saving associated with the reduction in medication burden, this is offset to some degree by the lack of improvement in $\mathrm{HbA}_{1 c}$ and the long-term complications associated with worsening glycaemic control.

The 8-week diet programme (Figure 1) was tailored to patient need, with $200 \mathrm{kcal}$ per day for patients to choose a vegetablebased meal to cook themselves from recipes provided by the department. While this pragmatic approach does reduce the controlled nature of the VLCD regime, it also offers some notable advantages; encouraging cooking, particularly vegetable-based cooking, may help facilitate long-term behaviour change for the better and thus maintenance of weight loss. ${ }^{25-27}$ Additionally, qualitative analysis of patient satisfaction with VLCD in T2DM has revealed that lack of variation in the diet is a risk factor for poor compliance ${ }^{28}$ introducing this element of choice may facilitate improved satisfaction and thus potentially improve concordance with the regimen. Our results show that an element of patient choice can be safely incorporated within a VLCD programme without compromising efficacy.

The VLCD programme at our institution incorporates a significant amount of patient education, both in groups and on a oneto-one basis, centring around improving patient understanding of T2DM. It is well acknowledged that multimodal patient education plays a pivotal role in promoting health behaviour change and reducing long-term complications associated with T2DM through improved self-care. $25,27,29$ Empowering patients with the knowledge to understand their glycaemic control and the mechanism by which VLCD might improve their T2DM in turn may well support longterm results beyond the VLCD follow-up. ${ }^{30}$ Further work is needed to evaluate the effect of VLCD education (including different educational tools) on long-term glycaemic and metabolic outcomes, as well as qualitative analysis of patient experience and the effect of socio-demographics on outcomes. In future, the ongoing NHS England Low Calorie Diet pilot may shed light on some of these outcomes; individuals undertaking a low-calorie diet will be supported to achieve their goals via either group, one-to-one or digital/appbased support, and comparison of outcomes between these methods as well as patient experience may facilitate more tailored support for individuals undertaking low-calorieNLCD in future. ${ }^{31}$

Despite our study providing important real-world outcomes to support RCT data, we acknowledge there are a number of limitations to our work. Firstly, retrospective data collection raises the possibility of a greater degree of influence due to unmeasured confounders, and also to selection and misclassification bias although every effort was made to minimise these by having two data collectors corroborate entries whenever unclear. In addition, there is a lack of control arm in our study. Our data do not include information on baseline socio-demographic difference, lipid profiles, blood pressure or markers of liver dysfunction; heterogeneity in reporting and timing of measurements introduced a large degree of confounding into these data and thus the results were not analysed. Further prospective work will ensure standardisation in such data collection. Furthermore, data are not available for the referral rate to the service nor the dropout rate amongst participants who did not complete the course. Due to the retrospective nature of the study and the changes in provision as the service developed, accurate data surrounding the cost implications of running a VLCD service have not been accurately captured; further prospective work should aim to undertake formal cost analyses.

\section{Conclusion}

Our study demonstrates a significant reduction in weight to 12 months post-VLCD in a heterogeneous group of patients with T2DM. Additionally, our work shows that a VLCD programme can be safely and successfully delivered with modifications from clinical trial protocols that allow for a more pragmatic approach in the real-world clinical setting. Further prospective studies assessing long-term efficacy in multiple metabolic parameters are required to validate the findings of this study. 


\section{Conflict of interest None. \\ Funding None.}

Contributorship MN and SM contributed to the study design, data collection, data analysis, writing and revision of the manuscript. RL and VW contributed to data collection and writing and revision of the manuscript. MR, EJ and $A D$ contributed to study design, writing and revision of the manuscript. LNRB was responsible for the study concept and contributed to study design, writing and revision of the manuscript.

\section{References}

1. Nield L, Moore HJ, Hooper L, et al. Dietary advice for treatment of type 2 diabetes mellitus in adults. Cochrane Database Syst Rev 2007(3): CD004097. https://doi.org/10.1002/14651858.CD004097.pub4

2. Berk K, Bujks H, Ozcan B, van't Spijker A, Busschbach J, Sijbrands E. The Prevention Of WEight Regain in diabetes type 2 (POWER) study: the effectiveness of adding a combined psychological intervention to a very low calorie diet, design and pilot data of a randomized controlled trial. BMC Public Health 2012;12:1026. https://doi.org/10.1186/1471-2458-12-1026

3. Roglic G, Unwin N. Mortality attributable to diabetes: estimates for the year 2010. Diabetes Res Clin Pract 2010;87:9-15. https://doi.org/10.1016/ j.diabres.2009.10.006

4. Diabetes UK. The Cost of Diabetes Report. 2012. Available from: www.diabetes.org.uk

5. Mokdad AH, Ford ES, Bowman BA, et al. Diabetes trends in the U.S.: 1990 1998. Diabetes Care 2000;23(9):1278-83. https://doi.org/10.2337/ diacare.23.9.1278

6. Gregg EW, Chen $\mathrm{H}$, Wagenknecht LE, et al. Association of an intensive lifestyle intervention with remission of type 2 diabetes. JAMA 2012; 308(23):2489-96. https://doi.org/10.1001/jama.2012.67929

7. Pucci A, Tymoszuk U, Cheung WH, et al. Type 2 diabetes remission 2 years post Roux-en-Y gastric bypass and sleeve gastrectomy: the role of the weight loss and comparison of DiaRem and DiaBetter scores. Diabet Med 2018;35(3):360-7. https://doi.org/10.1111/dme.13532

8. Park JY. Prediction of type 2 diabetes remission after bariatric or metabolic surgery. J Obes Metab Syndr 2018;27(4):213-22. https://doi.org/10.7570/ jomes.2018.27.4.213

9. Nagi D, Hambling C, Taylor R. Remission of type 2 diabetes: a position statement from the Association of British Clinical Diabetologists (ABCD) and the Primary Care Diabetes Society (PCDS). Br J Diabetes 2019;19(1):73-6. https://doi.org/10.15277/bjd.2019.221

10. Lim EL, Hollingsworth KG, Aribisala BS, Chen MJ, Mathers JC, Taylor R. Reversal of type 2 diabetes: normalisation of beta cell function in association with decreased pancreas and liver triacylglycerol. Diabetologia 2011; 54(10):2506-14. https://doi.org/10.1007/s00125-011-2204-7

11. Lean MEJ, Leslie WS, Barnes AC, et al. Primary care-led weight management for remission of type 2 diabetes (DiRECT): an open-label, cluster-randomised trial. Lancet 2018;391(10120):541-51. https://doi.org/10.1016/S01406736(17)33102-1

12. Steven S, Hollingsworth KG, Al-Mrabeh A, et al. Very low-calorie diet and 6 months of weight stability in type 2 diabetes: pathophysiological changes in responders and nonresponders. Diabetes Care 2016;39(5):808-15. https://doi.org/10.2337/dc15-1942

13. Bhatt AA, Choudhari PK, Mahajan RR, et al. Effect of a low-calorie diet on restoration of normoglycemia in obese subjects with type 2 diabetes. Indian J Endocrinol Metab 2017;21(5):776-80. https://doi.org/10.4103/ ijem.IJEM_206_17

14. Clinical Guidelines on the Identification, Evaluation, and Treatment of Overweight and Obesity in Adults--The Evidence Report. National Institutes of Health. Obes Res 1998 Sep;6 Suppl 2:51S-209S. Erratum in: Obes Res 1998 Nov;6(6):464. PMID: 9813653.
15. Amatruda JM, Richeson JF, Welle SL, Brodows RG, Lockwood DH. The safety and efficacy of a controlled low-energy ('very-low-calorie') diet in the treatment of non-inuslin-dependent diabetes and obesity. Arch Intern Med 1988; 148(4):873-7.

16. Taylor R. Banting Memorial lecture 2012: reversing the twin cycles of type 2 diabetes. Diabet Med 2013;30(3):267-75. https://doi.org/10.1111/ dme.12039

17. Taylor R. Type 2 diabetes: etiology and reversibility. Diabetes Care 2013; 36(4):1047-55. https://doi.org/10.2337/dc12-1805

18. Jackness C, Karmally W, Febres $G$, et al. Very low-calorie diet mimics the early beneficial effect of Roux-en-Y gastric bypass on insulin sensitivity and beta-cell function in type 2 diabetic patients. Diabetes 2013;62(9):302732. https://doi.org/10.2337/db12-1762

19. Dombrowski SU, Knittle K, Avenell A, Araujo-Soares V, Sniehotta FF. Long term maintenance of weight loss with non-surgical interventions in obese adults: systematic review and meta-analyses of randomised controlled trials. BMJ 2014;348:g2646. https://doi.org/10.1136/bmj.g2646

20. Kloecker DE, Zaccardi F, Baldry E, Davies MJ, Khunti K, Webb DR. Efficacy of low- and very-low-energy diets in people with type 2 diabetes mellitus: a systematic review and meta-analysis of interventional studies. Diabetes Obes Metab 2019;21(7):1695-705. https://doi.org/10.1111/dom.13727

21. Leslie WS, Ford I, Sattar N, et al. The Diabetes Remission Clinical Trial (DiRECT): protocol for a cluster randomised trial. BMC Fam Pract 2016; 17:20. https://doi.org/10.1186/s12875-016-0406-2

22. Snel M, Jonker JT, Hammer S, et al. Long-term beneficial effect of a 16week very low calorie diet on pericardial fat in obese type 2 diabetes mellitus patients. Obesity (Silver Spring) 2012;20(8):1572-6. https://doi.org/ 10.1038/oby.2011.390

23. Rolland C, Mavroeidi A, Johnston KL, Broom J. The effect of very low-calorie diets on renal and hepatic outcomes: a systematic review. Diabetes Metab Syndr Obes 2013;6:393-401. https://doi.org/10.2147/DMSO.S51151

24. Rueda-Clausen CF, Ogunleye AA, Sharma AM. Health benefits of long-term weight-loss maintenance. Annu Rev Nutr 2015;35:475-516. https://doi.org/10.1146/annurev-nutr-071714-034434

25. Cradock KA, G OL, Finucane FM, Gainforth HL, Quinlan LR, Ginis KA. Behaviour change techniques targeting both diet and physical activity in type 2 diabetes: a systematic review and meta-analysis. Int J Behav Nutr Phys Act 2017;14(1):18. https://doi.org/10.1186/s12966-016-0436-0

26. Forouhi NG, Misra A, Mohan V, Taylor R, Yancy W. Dietary and nutritional approaches for prevention and management of type 2 diabetes. BMJ 2018; 361:k2234. https://doi.org/10.1136/bmj.k2234

27. Akhter K, Bunn C, Graffy J, Donald S, Ward C, Simmons D. Empowermentbased education for established type 2 diabetes in rural England. Pract Diabetes Int 2017;34(3):83-8. https://doi.org/10.1002/pdi.2088

28. Rehackova L, Araujo-Soares V, Adamson AJ, Steven S, Taylor R, Sniehotta FF. Acceptability of a very-low-energy diet in type 2 diabetes: patient experiences and behaviour regulation. Diabet Med 2017;34(11):1554-67. https://doi.org/10.1111/dme.13426

29. Zhang Y, Chu L. Effectiveness of systematic health education model for type 2 diabetes patients. Int J Endocrino/ 2018;2018:6530607. https://doi.org/ 10.1155/2018/6530607

30. Herenda S, Tahirovic H, Poljakovic D. Impact of education on disease knowledge and glycaemic control among type 2 diabetic patients in family practice. Bosnian J Basic Med Sci 2007;7(3):261-5. https://doi.org/10.17305/ bjbms.2007.3056

31. NHS England. Low calorie diets to treat obesity and type 2 diabetes. 2020. Available from: https://www.england.nhs.uk/diabetes/treatment-care/lowcalorie-diets/ 